
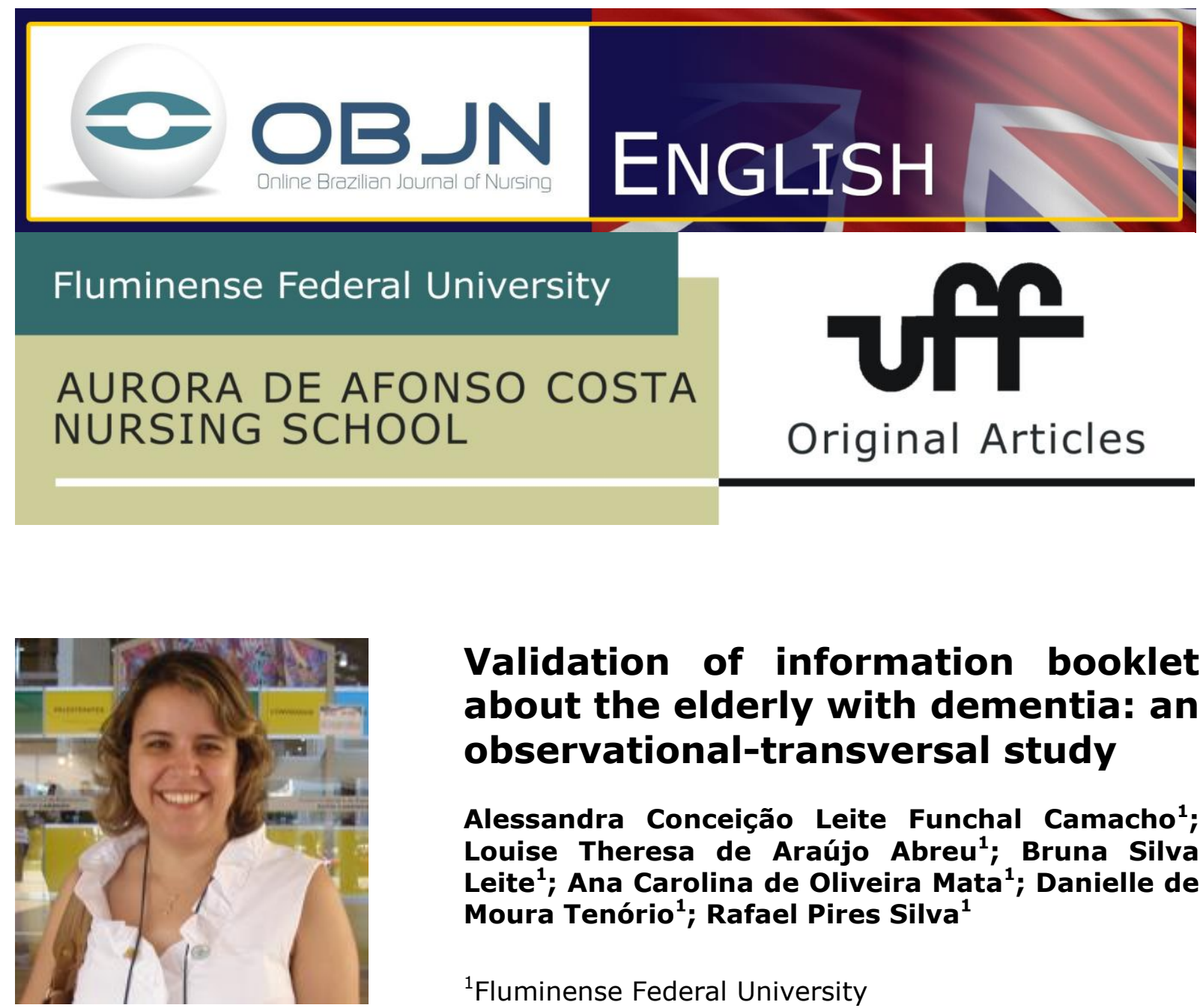

\title{
Validation of information booklet about the elderly with dementia: an observational-transversal study
}

\begin{abstract}
Alessandra Conceição Leite Funchal Camacho'; Louise Theresa de Araújo Abreu ${ }^{1}$; Bruna Silva Leite $^{1}$; Ana Carolina de Oliveira Mata ${ }^{1}$; Danielle de Moura Tenório'; ${ }^{1}$ Rafael Pires Silva ${ }^{1}$
\end{abstract}

${ }^{1}$ Fluminense Federal University

\begin{abstract}
Aim: to validate an information Educational Technology (ET) booklet about the care of the elderly with dementia.

Method: This is an observational study using a transversal approach, where the selected study environment is a College education institution in the state of Rio de Janeiro. The research focused on caregivers and relatives. The data collection period was from April to June 2012.

Results and Discussion: The analysis of the evaluators decided that the validation of the booklet was satisfactory, as the majority of the answers demonstrated adequate results without any important variation. Based on the parameter of evaluation and its evaluation items, the booklet meets many of the proposed goals, therefore achieving the proposed final objective.

Conclusion: The validated booklet can contribute to the care of people with dementia, thereby preventing complications. It also helps to develop the abilities of users and facilitates the autonomy and motivation of the nursing team in terms of creating new educational technology instruments.
\end{abstract}

Descriptors: Aged, Dementia, Nursing, Educational Technology. 


\section{INTRODUCTION}

The Brazilian census registered, in 2009, 9.7 million elderly people above the age of 70 . This corresponds to $5.1 \%$ of the total population of the country. The number of the elderly population in Brazil is higher if we consider the inhabitants above the age of 60, adding 21.7 million inhabitants to the previous number, thus corresponding to more than $11 \%$ of the total population in the country ${ }^{(1)}$.

This scenario generates a specific demand on the health service and, in the case of nursing, the need for a qualified healthcare service to deal with these clients. For epidemiologists, this situation reflects a real challenge, as there is a rise in the number of people with dementia due to the increase in longevity.

Dementias need still more study and an increased awareness within society because, although there is research into these pathologies, in many aspects they are still unspecified, and not completely presented to the population ${ }^{(2)}$.

In a large number of the articles located by this study, the difficulty observed was that the majority of them were not completely free online. It would be more beneficial to researchers and other people interested in the topic if there was free online availability of such studies, in order to make accessible the most comprehensive clarifications of dementia, which is a growing requirement in contemporary society due to the rise in the number of older citizens ${ }^{(2)}$. The information regarding the elderly with a dementia disorder is a constant source of debate within academia, on the part of nursing professionals, and for the multidisciplinary teams. It could also aid caregivers and relatives who are involved in caregiving ${ }^{(3)}$.

The understanding of the family dynamics of the elderly with dementia is relevant because such an understanding permits the prevention of potential dangers and considering all family members as being involved in caregiving procedures. Therefore, 
the nurse must consider, from the perspective of continuous planning, the relative/caregiver as an active part of the process of caregiving, as the relationships associated with familiar coexistence are clearly present.

The family usually provides the support for the elderly individual. However, some problems can affect the process of caregiving by the relatives, such as the family caregiver is an also an elder, there may be a reduced network of relatives, caregiving can lead to an overload, there may be a lack of responsibility in terms of caregiving, there may be an impact of the disorder in daily life, there may be difficulties continuing the development of the treatment and there may be a lack of emotional support for the caregivers.

In order to provide effective support to the relatives/caregivers, it is important to focus on the state of balance of the elder in terms of dementia and the clinical state of the illness. This demands a range of qualities on the part of the caregiver, and it can lead to an understanding of the high incidence of complications related to daily tasks, demanding nursing care planning linked to the reality of the situation faced by the client ${ }^{(3)}$.

There is a need for an educational process that embraces the specificities of elderly clinic. This should incorporate progressive educational developments and the use of educational technologies on the part of professionals, involving the participation of stakeholders. This should be based on democracy and citizenship with the different groups of the population $^{(4)}$.

Within this perspective, after sharing the understandings with relatives and caregivers of the elderly with dementia, this study aimed to validate an educational technology instrument, in the form of an information booklet. This booklet aims to provide information about the developmental stages of dementia so that the target audience can better observe the problems they face in such a way as to allow them maintain a state of balance. 
The justification for developing such a booklet is based on three premises: the problems that originate from the conflicts that emerge can be alleviated through the provision of consistent guidelines; the vulnerability of the person with dementia disorders must be understood by relatives and/or caregivers as a real issue, and this requires effective action to continue the treatment and; the need for the permanent education of nursing professionals in terms of the specifics of nursing care as it relates to the elderly, as well as the development of a continuous support network to aid relatives and/or caregivers.

We believe that the information booklet relating to the caregiving of the elder with dementia can provide an education that can enhance the quality of life, as it is a source of information, helping the active participation of relatives and/or caregivers, permitting and motivating self-care, contributing to the situation which encourages the elderly to have better chances of survival, better wellbeing and an improved state of balance. Therefore, the validation of this booklet has important implications for nursing care, nursing education and university research.

\section{METHOD}

This is an observational study using a transversal approach. The scenario for this study was a College education institution, located in the municipality of Niterói, Brazil. The research project tried to validate an information booklet about healthcare procedures with regard to the elderly diagnosed with dementia, as an educative technology (ET) instrument and as a strategic tool to be used practically by nursing professionals, caregivers and relatives.

In terms of the observational study, the researchers simply observe the patient, and the characteristics of the illness/disorder and its evolution, without interfering or modifying any aspects that are being observed. In accordance with the transversal approach, there is the presentation of a population sample, the examination of this sample, the presence 
or lack of exposition, and the effect (e.g. illness or another elements of the analysis). The main advantages are the low cost and the lack of any loss in sequence ${ }^{(5)}$.

The inclusion criteria of the subjects are: be a relative or caregiver of an elderly person diagnosed with dementia; understand the activities developed as part of the Facilitating Action Project (Projeto Ações Facilitadoras, in Portuguese) that is part of the Program PRÓ-CUIDEM and; be willing to participate voluntarily in this study according to Resolution 196/1996.

The data collection technique used consisted of a semi-structured questionnaire with closed questions $^{(6)}$. This method has many different advantages, such as the possibility of reaching a great number of people; lower staff costs as it does not demand any additional training; time saving; anonymity of responses; lower risk of distortion due to bias on the part of the researcher and; more time to answer the questions in a more flexible manner. The instrument was applied to a sample composed of 22 relatives and caregivers (target-group) between the months of April and June 2012.

The instrument used in the sample was composed of two parts. In Part I, there were requests for identification information in the form of years of education and age; Part II was subdivided into several different sections: Section 1 - objectives of the booklet (for the ET target-group, use of the ET by the target-group, and for any caregiver that works in the field of the ET target-group); Section 2 - organization of the booklet (presentation, size of the title, sequence and proper content, coherence of the information, appropriateness, suggestions of websites and other important aspects);

Section 3 - writing style (adequacy, interesting text, accessible vocabulary, association with the topic, clarity and writing corresponding to the level of understanding of the target-group); Section 4 - appearance (organization, simple illustrations, complementary illustrations and expressiveness/adequacy of the illustrations); Section $\mathbf{5}$

- motivation (appropriateness of the material, logicality of the content, interactivity of the text that suggests actions, description of necessary topics, attempts to change the 
behavior and attitude of the target-group, gathering of information to enrich the targetgroup) and; a space for general comments and suggestions by the responding subjects.

It is important to highlight that in Part II this instrument has the following values which the informants can select: 1-Totally adequate (TA); 2-Adequate (A); 3-Partly adequate (PA) e; 4-Inadequate (I).

Four orientation meetings took place with relatives and caregivers, based on the following agenda:

- First Meeting: General information about the dementia process. In this meeting, the types of dementia were introduced, as well as the ten most common signs of dementia, the pathologies that come with the illness, Alzheimer disease, and the stages of dementia.

- Second Meeting: General information about medication. During this second meeting we introduced the types of pharmaceuticals used, their objectives, the management of such drugs, the most common side effects and basic care.

- Third Meeting: In this meeting the discussion was about daily challenges of the dementia process - there were debates about the information regarding the caregiving of the elderly at home, such as clothing, bathing and hygiene, as well as strategies to promote self-care, alternatives found and suggested to allow a better coexistence with the elderly with dementia, not forgetting to mention the safety issues in the home environment.

- Fourth Meeting: Basic instructions in cognitive stimulation were examined - the need to keep the mind of the elderly relative active in order to slow down the development of dementia. During this meeting, suggestions were made on how to stimulate the elderly at home. Common instruments found in our daily routine were presented and it was explained how these daily instruments could be use with an elderly relative at home in terms of the dementia process. 
Following the meetings, the activities were evaluated and the data collection instrument was used to improve the information provided to the caregivers in the booklet, as well as the development of a student in a scientific scholarship program by Rio de Janeiro Research Support Foundation (FAPERJ, in Portuguese), tutored by the professor-project coordinator.

It is important to mention that the present project was approved by the Ethics in Research Committee of the University Hospital Antônio Pedro, of the Fluminense Federal University, according to Resolution 196/1996 of the Brazilian National Health Council, under protocol \#0363.0.258.000-11, register 347, of November 2011.

The answers obtained from the use of the data collection instrument were grouped and categorized in order to generate a data bank the information from which was then treated statistically (simple statistics) in absolute and percentage data terms so that the numerical results did not lose their importance. The methodological proceedings are synthesized in the flowchart presented below.

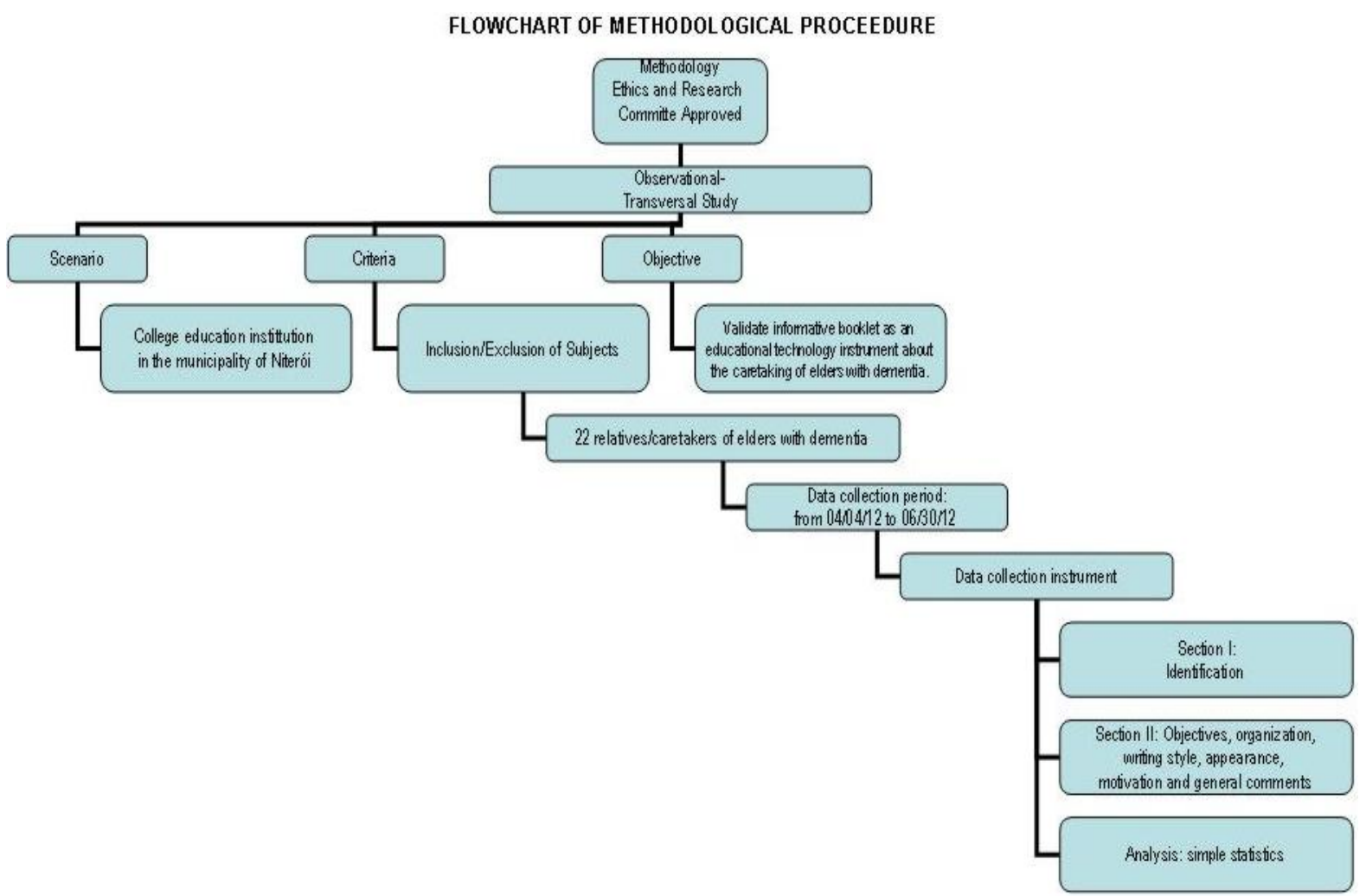




\section{RESULTS}

The target-group (caregivers/relatives) was composed by 22 people, seven of whom were placed in the first group (31.8\%) and 15 in the second group (68.2\%). Of the participants, $18(81.82 \%)$ were female and four $(18.18 \%)$ were male. They were between the ages of 30 and 89 years of age, with an average of 60 years. Regarding their level of education, $14 \%$ had finished Middle School; $59 \%$ had finished High School; $9 \%$ were College dropouts and $18 \%$ had College degrees.

\section{- Analysis of the answers from the target-group}

From the answers given by the target-group, in SECTION 1, we can validate the booklet regarding the proposition, aims or objectives that were to be achieved with its use. This section had only three items: the maximum number of responses was 66 , as the targetgroup was composed of 22 people, therefore: 3 (items) multiplied by 22 (people) $=66$ (responses).

The answers were: 45 TA (Totally Adequate), 16 A (Adequate), 3 PA (Partly Adequate) and zero I (Inadequate). Thus, from the total of 66 possible responses (100\%), 61 (92.4\%) were TA and $A$. We can affirm that the three items of this section were validated, as they achieved $80 \%$ or more TA and A answers.

Item 1.1 refers to the fulfillment of the objectives established by the target-group, which was $100 \%$ approved; item 1.2 asks if the ET helps during the caregiving process, and this was agreed in $95 \%$ of the cases with $5 \%$ abstentions; item 1.3 was related to the adequacy of the ET for its use by any professional that works in the field of the targetgroup. It achieved an $82 \%$ approval rate with $4 \%$ of abstentions.

The validation of SECTION 2 of the booklet was connected to the design of the presentation of the information, including the general organization, the structure, the presentation strategy, its coherence and formatting. The maximum number of responses 
in order to validate this section of seven items was 154 in that 7 (items) multiplied by 22 $($ people $)=154($ responses $)$.

The answers were 100 TA, 31 A, 13 PA and one I. Therefore, from the 154 respondents (100\% of possible points), $131(85.06 \%)$ were TA and $A$. As a consequence, the seven items of this section were validated, as they all presented approval rates above the $80 \%$ mark if we sum the TA and A answers.

Item 2.1 related to the attractiveness of the booklet cover. This achieved a $77 \%$ approval rate with $5 \%$ abstentions. With regard to this item there was an area in which to write comments. Some related to the use of a colored cover. Item 2.2 analyzed the size of the title and the adequacy of the topics, achieving an $86 \%$ approval rate and $9 \%$ abstentions. Item 2.3 questioned the sequence of topics and achieved an $87 \%$ approval rate and $4 \%$ abstentions.

Item 2.4 of Section 2, regarding the coherence of the information presented on the cover, the back cover, in the summary, in terms of acknowledgements and/or presentation, achieved an $86 \%$ approval rate and 5\% abstentions. Some comments suggested the need for a better binding in order to sustain the life of the ET. Item 2.5 asked for comments on the appropriateness of the material and had an $82 \%$ approval rate with $5 \%$ abstentions. Item 2.6 referred to the adequacy of the number of pages, and achieved a 78\% approval rate with 13\% abstentions. Item 2.7 asked if the topics reflected important issues, and achieved a $9 \%$ approval rate and $4 \%$ abstention.

The validation of SECTION 3 dealt with the linguistic characteristics, the level of comprehension and the writing style used in the booklet. This section of six items could achieve a maximum of 132 responses, as 6 (items) multiplied by 22 (people) $=132$ (possible responses). 
The answers were: 98 TA, 25 A, 4 PA and zero I. Therefore, as can be observed, 123 (93.2\%) of the answers were TA and A, validating the six items because they achieved approval rates above $80 \%$ if summing all TA and A answers.

Item 3.1 asked the respondents about the quality of the writing and had a $95 \%$ approval rate. Item 3.2 asked if the text was interesting and it was approved by $95 \%$ of the respondents, with $5 \%$ abstentions. Item 3.3 validated the accessibility of the vocabulary used, with $95 \%$ approvals and 5\% abstentions. Item 3.4 associated the topic of each section to the corresponding text and this aspect was approved with a $96 \%$ rate and $4 \%$ abstentions. Item 3.5 validated the clarity of the text with a $96 \%$ approval rate, while abstentions with regard to this item was $4 \%$. Finally, in terms of item 3.6, which links the writing style to the level of education of the target-group, the items achieved a $91 \%$ approval rate and $5 \%$ abstentions.

The validation of SECTION 4 of the booklet related to the degree of significance of the educational material presented. This section has four items. However, three of them (4.2, 4.3 and 4.4) are not applicable to this study, as the booklet does not have any illustrations. As only one item was evaluated, the maximum number of responses available to validate this section was 22 , as 1 (item) multiplied by 22 (people) $=22$ (possible responses).

The answers were: 17 TA, 4 A, 1 PA and zero I. From the 22 possible responses $(100 \%)$, $21(95.4 \%)$ were TA and A. It is possible to confirm that this section was validated, as it presented an approval rate above $80 \%$ in terms of TA and A answers. Item 4.1 deals with the organization of pages or sections, reaching a $95 \%$ approval rate However, the comments suggested the need to use illustrations to improve the learning experience.

The validation of SECTION 5 referred to the capacity of the material to have an impact and to increase motivation and/or interest. In addition, it evaluated the meaning of the 
educational instrument. This section has six items, therefore the validation limit was 132 responses, because: 6 (items) multiplied by 22 (people) - 132 (possible responses).

The answers were as follows: 91 TA, 30 A, 3 PA and one I. Thus, from a 132 possible responses (or 100\%), 121 of them (or $91.26 \%$ ) consisted of TA and A. The six items of contained in this section were validated, because all approval rates were above $80 \%$ if summing all TA and A answers.

Item 5.1 is about the appropriateness of the material according to the profile of the target-group, achieving a $95 \%$ approval rate. Item 5.2 refers to the logicality of the contents, with an $87 \%$ approval rate and $9 \%$ abstentions. Item 5.3 focused on the stimulus to interactivity by suggesting a number of actions and got an approval rate of $91 \%$ with $9 \%$ abstentions. Item 5.4 mentions the extent to which the ET deals with subjects necessary to the daily routine of the target-group, and achieved a $95 \%$ approval rating with $5 \%$ abstentions. Some comments were made, suggesting the need for a consideration of psychological aspects and actions with regard to daily routines.

Item 5.5 asked if the ET instigates changes in behavior and attitudes. These aspects were awarded with an $87 \%$ approval rate and a $4 \%$ abstention rate. Some respondents recommended the provision of more practical advice. Item 5.6 asked the respondents to clarify whether or not the ET proposes new understandings to the target-group. This was agreed by $95 \%$ of the subjects, while $5 \%$ of them did not respond.

In the general comments and suggestions area, the target-group informed the researchers that the texts of the booklet was interesting and clarifying, and improved the respondents' understanding of dementia. They had meetings using the booklet, because they viewed these meetings as a practical strategy for improving their understanding and as a way to clear away doubts about dementia in the way that they wanted. They were of the opinion that any sort of interaction with the public was a valid one. 
The importance of psychologic and action orientations as part of the daily routine, followed by some practical suggestions, was also mentioned in the commentaries. In addition, other suggestions included the need for a wider distribution of the booklet as many people need such a publication in that few have access to information of this type. Generally speaking, it was felt that normally the health service does not acknowledge how to deal with this sort of problem.

When referring to the appearance of the booklet, the respondents highlighted the need for a better binding, to better maintain the booklet, the need for illustrations and a colored cover. Suggestions about additional books and handouts containing further information were also recommended.

\section{DISCUSSION}

Caregivers and relatives need support regarding the physical and psycho-behavioral problems found in caring for the elderly. Such support needs to be transmitted by health professionals, especially nursing staff, through an educational health program. The process of education must deal with an evaluation of the understanding of caregivers, so that new concepts about the illness and caregiving interventions can be developed ${ }^{(7)}$. The development understanding on the part of caregivers and relatives about the health problems of the elderly with dementia has helped the researchers to have a reflexive oversight over the contents of the booklet.

Thus, it is essential to identify the caregiver as a subject that also needs to be considered during planning for healthcare and during the nursing routines, from the perspective that it is necessary that the caregiver is well informed, in order to be able to provide the dignified care of the elderly with dementia that is necessary. Nursing, together with its understanding and professional competences, can contribute to building new models of healthcare of the elderly diagnosed with dementia ${ }^{(8)}$, not only to ensure the quality of healthcare for such patients, but also to care for the relatives/caregivers of this clientele. 
Based on the results of the validation of the booklet as an educational technology instrument, we observed that, regarding the aim of the instrument, the incorporation of new information allowed a learning process to take place from the perspective of the multiple potentials, capabilities and interests of the learners. Such a fact can individualize the learning process and contribute to the construction of a collective learning experience $^{(9)}$.

In terms of the organization in the educational health practices, the technological instrument can be used to enhance the participation of the subjects within the educational process, contributing to build citizenry and a rise in the autonomy of the patients/caregivers involved. Therefore, it is necessary to explore the resources that match the recognized and valued cultural meanings within the context of the users and of the whole community ${ }^{(10)}$.

It was observed that the appearance and writing style can be used to amplify our understanding of the information sent through spatial and visual abilities. In addition, such approaches can be incorporated in the present exchange about converging and similar topics(9) related to dementia.

Through communication and information technology, nurse educators involved in the process of mutual exchange with caregivers and relatives can improve the usage of this tool to teach, aiming to develop the inclusion of experiences, and to adapt the technology. This implies a constant updating and validation of this educational instrument $^{(11)}$.

The evaluation of caregivers and relatives of the elderly with dementia is necessary, because, in this study, we have showed the relevance of awareness about the use of this technological instrument as a learning process, its development, the possible users of this ET, and their concepts. In addition, the production of instruments such as the booklet is a credible low cost alternative. 
To go beyond a transforming education, the item structure and presentation of the data collection instrument meshes with the needs of the participants and enables nursing staff to experiment with the use of new educational approaches. as well as the development of effective technological instruments that can enhance nursing care ${ }^{(12)}$.

It can be seen that in terms of the item relevance, the technologies refer to the educational strategies used to stimulate healthy behavior through the learning of new abilities in healthcare when dealing with the health-illness process ${ }^{(12)}$. In the case of caregivers, the nurse is directly connected to the cognitive problems presented by the elderly as part of their daily routines, and to the caregivers through the course of the scheduled meetings which were perceived as being highly relevant.

For the families that were studied, dependency or aging are taken as aspects that are inherent to life, and that it is expected that the elderly will live with their families in spite of the difficulties when it comes to managing daily routines emerge ${ }^{(13)}$. In this sense, the daily ordinary situations are considered to be more significant according to the particular situation of each relative caregiver.

\section{CONCLUSION}

The experience described in this study, to validate a booklet about the care of the elderly diagnosed with a dementia disorder can be extended to other scenarios and applied to other topics of interest. This technology can be used in health educational practices in general, as it is a strategy based in simple, attractive and specific language.

The results obtained show that it is important to adopt technologies that incorporate new learning methods. For example, the booklet which is the object of this study, offers a variety of sources of information important to health education.

The evaluation of caregivers/relatives shows that the booklet offers the possibility of the acquisition of information about the topic under consideration, generating changes in the 
behavior and healthcare practices offered to the elderly with dementia by the caregivers. The creation of new understandings facilitates the capacity to produce and readapt new technological resources.

Therefore, the activities developed through educational technology instruments such as this booklet, can respond to a health education that is based in actions that recognize the real needs, desires and aspirations of the relatives/caregivers.

The booklet will have appropriate adaptations made to answer the real needs of the clientele, based on the recommendations provided by the relatives/caregivers a part of this research. From this it is concluded that it is important to schedule meetings that aim to guide stakeholders and to develop an understanding of the process of dementia in the elderly.

\section{REFERENCES}

1.Instituto Brasileiro de Geografia e Estatística. Perfil dos Idosos Responsáveis Pelos Domicílios no Brasil de 2010. Rio de Janeiro: IBGE; 2010.

2.Araújo CLO, Nicoli JS. Uma revisão bibliográfica das principais demências que acometem a população brasileira. Rev. Kairós [ serial on the Internet ]. 2010 Jun [ cited 2012 Jul 27 ] 13(1): 231-44. Available from: http://revistas.pucsp.br/index.php/ kairos/article/view/4872/3458

3.Camacho ACLF, Chaves Sá SP, Lindolpho MC, Valente GSC, Brum AKR, Abreu LTA. Blog Interativo sobre os Cuidados ao Idoso com Doença de Alzheimer e Outros Transtornos Demenciais: Relato De Experiência. Rev pesqui cuid fundam online [ serial on the Internet ]. 2011 October [ cited 2012 Jan 27 ] 3 (4): 2500-8. Available from: http://www.seer.unirio.br/index.php/cuidadofundamental/article/view/1494.

4.Teixeira E, Mota VMSS. Tecnologias Educacionais em Foco. São Paulo: Difusão Editora; 2011. 
5.Hulley SB, Cummings SR, Browner WS, Grady DG, Newman TB. Delineando a pesquisa clínica: uma abordagem epidemiológica. Porto Alegre: Artmed; 2008.

6.Oliveira MS, Fernandes AFC, Sawada NO. Manual educativo para o autocuidado da mulher Mastectomizada: um estudo de validação. Texto \& contexto enferm [ serial on the Internet ]. 2008 January [ cited 2012 Jan 27 ] 17 (1): 115-23. Available from: http://www.scielo.br/pdf/tce/v17n1/13.pdf.

7.Valente LE, Truzzi A, Souza WF, Alves GS. Autopercepção de saúde em cuidadores familiares de pacientes com demência: fatores sociodemográficos e clínicos. Arq neuropsiquiatr [ serial on the Internet ]. 2011 October [ cited 2012 Jul 27 ] 69(5): 73944. Available from: http://www.scielo.br/pdf/anp/v69n5/a02v69n5.pdf

8.Lenardt MH, Willig MH, Seima MD, Pereira LF. A condição de saúde e satisfação com a vida do cuidador familiar de idoso com Alzheimer. Colomb méd [ serial on the Internet ]. 2011 June [ cited 2012 Jul 27 ] 42 suppl 1: S17-25. Available from: http://colombiamedica.univalle.edu.co/index.php/comedica/article/view/816/1347

9.Costa JB, Peres HHC, Rogenski NMB, Baptista CMC. Proposta educacional on-line sobre úlcera por pressão para alunos e profissionais de enfermagem. Acta paul enferm [ serial on the Internet ]. 2009 October [ cited 2012 Feb 01 ] 22 (5): 607-11. Available from: http://www.scielo.br/pdf/ape/v22n5/02.pdf.

10.Martins ÁKL, Nunes JM, Nóbrega MFB, Pinheiro PNC, Souza AMA, Vieira NFC et al. Literatura de cordel: tecnologia de educação para saúde e enfermagem. Rev enferm UER] [ serial on the Internet ]. 2011 April [ cited 2012 Feb 01 ] 19 (2): 324-9. Available from: http://www.facenf.uerj.br/v19n2/v19n2a25.pdf.

11.Silveira DT, Catalan VM, Neutzling, Martinato LHM. Digital Learning Objects in Nursing Consultation: Technology Assessment by Undergraduate Students. Rev Latino-Am 
Enfermagem [ serial on the Internet ]. 2010 September [ cited 2012 Feb 01 ] 18 (5): 1005-12. Available from: http://www.scielo.br/pdf/rlae/v18n5/23.pdf.

12.Gubert FA, Santos ACL, Aragão KA, Pereira DCR, Vieira NFC, Pinheiro PNC. Tecnologias educativas no contexto escolar: estratégia de educação em saúde em escola pública de Fortaleza-CE. Rev eletrônica enferm [ serial on the Internet ]. 2009 January [ cited 2012 Feb 01 ] 11 (1): 165-72. Available from: http://www.fen.ufg.br/revista/v11/ n1/v11n1a21.htm.

13.Silva L, Bousso RS, Galera SAF. Convivendo com um idoso dependente sob a perspectiva da família: um estudo qualitativo. Online braz $\mathrm{j}$ nurs [ serial on the Internet ]. 2010 January [cited 2012 Aug 07] 9 (1). Available from: http://www.objnursing.uff.br/ index.php/nursing/article/view/j.1676-4285.2010.2887/648.

Received: 07/08/2012

Approved: 05/02/2013

\section{Each member of the research team participated in the research as follows}

Alessandra Conceição Leite Funchal Camacho ${ }^{1}$, Louise Theresa de Araújo Abreu2, Bruna Silva Leite ${ }^{2}$, Ana Carolina de Oliveira Mata ${ }^{3}$, Danielle de Moura Tenório ${ }^{4}$, Rafael Pires Silva ${ }^{4}$

${ }^{1}$ Conceived the main project and the development of the research; ${ }^{2}$ Collected the data and registered the meetings;

${ }^{3}$ Collected the data and generated the statistical analysis of the content; ${ }^{4}$ Collected the data and researched the bibliographical references to contextualize the content researched. 